J. Lake Sci.(湖泊科学), 2008, 20(5): 549-555

http://www.jlakes.org. E-mail: jlakes@niglas.ac.cn

(C)2008 by Journal of Lake Sciences

\title{
微囊藻衰亡过程研究一一四种模拟胁迫条件下微囊藻的衰亡生理*
}

\author{
李 杰 $^{1,2}$, 欧丹云 ${ }^{3}$, 宋立荣 $1^{* *}$ \\ (1: 中国科学院水生生物研究所淡水生态与生物技术国家重点实验室, 武汉 430072) \\ (2: 中国科学院研究生院, 北京 100049) \\ (3: 厦门大学海洋与环境学院, 厦门 361005)
}

摘 要: 研究了四种胁迫条件下微囊藻衰亡过程以及衰亡过程中生长生理与抗氧化酶系统的变化以及胁迫 $30 \mathrm{~d}$ 后转人正常培 养后的微囊藻的生长变化过程. 将对数生长期的微囊藻分别转人氮饥饿、磷饥饿、黑暗及 $10^{\circ} \mathrm{C}$ 低温等胁迫条件下培养, 测定 光密度 $\mathrm{OD}_{680}$ 、叶绿素 $\mathrm{a} 、$ 超氧化物歧化酶(SOD)和过氧化氢酶(CAT)活性等生理指标. 结果表明, 在黑暗和低温条件下, 微囊 藻生长受到明显抑制, 但黑暗条件下 $25 \mathrm{~d}$ 后微囊藻衰亡, 低温条件下仅需 $7 \mathrm{~d}$; 与物理因子引起的胁迫相比, 在营养胁迫条件 下, 微囊藻在胁迫前期均表现出生长趋势. $\mathrm{N}$ 饥饿条件下叶绿素 $\mathrm{a}$ 含量从开始胁迫后即下降, $\mathrm{P}$ 饥饿 $20 \mathrm{~d}$ 后叶绿素 $\mathrm{a}$ 含量以 $0.1 \mathrm{mg} /(\mathrm{L} \cdot \mathrm{d})$ 急剧下降, 在四种胁迫条件中下降速率最高, 表明微囊藻对 $\mathrm{P}$ 的耐受能力最差. 根据实验结果, 在长期没有外来 $\mathrm{P}$ 源供给而内部又无可得 $\mathrm{P}$ 源的水体中、或者水温急剧下降到 $10^{\circ} \mathrm{C}$ 以下时, 微囊藻水华可能会快速衰亡, 相应的应急措施应准 备到位, 以尽量减轻水体微囊藻水华衰亡带来的损失. SOD 与 CAT 活性的上升与叶绿素 a 含量的下降存在显著相关性, 可以 尝试将两者结合预测微囊藻水华的衰亡. 本研究在实验室条件下初步探讨了四种环境因子对微囊藻消亡的贡献, 比较了 SOD 与 CAT 活性与叶绿素 a 含量下降的相关性, 为微囊藻水华衰亡预测体系的建立提供了理论依据.

关键词: 微囊藻; 衰亡; 磷饥饿; 胁迫; 抗氧化酶系统

\section{Decline of Microcystis aeruginosa FACHB-905 under four stress conditions}

\author{
LI Jie $^{1,2}$, OU Danyun ${ }^{3} \&$ SONG Lirong ${ }^{1}$ \\ (1: State Key Laboratory of Freshwater Ecology and Biotechnology, Institute of Hydrobiology, Chinese Academy of Sciences, Wuhan \\ 430072, P.R.China) \\ (2: Graduate School of Chinese Academy of Sciences, Beijing 100049, P.R.China) \\ (3: College of Oceanography and Environmental Science, Xiamen University, Xiamen 361005, P.R.China)
}

Abstract: The present study aimed to evaluate the contribution of stress factors to the decline of Microcystis bloom, also tried to develop some indicator of decline. Four stress conditions including nitrogen starvation, phophorus starvation, dark and low temperature $\left(10^{\circ} \mathrm{C}\right)$ were designed. Decrease of biomass and the concomitant change of antioxidant system, including superoxide dismutase (SOD) and catalase (CAT) activities were detected. The result indicated that growth was significantly inhibited under dark and low temperature. Microcystis population declined after 25 days under dark, while declined after only 7 days under low temperature. Compared with the physical stress, nutrition such as nitrogen and phosphorus did not limit the growth effectively in the early stage. Chlorophyll-a decreased as soon as being incubated into nitrogen free BG-11 medium. After being kept in phosphorus free medium for 20 days, chlorophyll-a reached peak, about the twice of the initial concentration, and then decreased at a rate of $0.1 \mathrm{mg} /(\mathrm{L} \cdot \mathrm{d})$, which was the highest decaying rate among the four factors. It indicated its significance of available phosphorus for Microcystis survival and decline. According to the results, when phosphorus was limited, or water temperature was decreased to $10^{\circ} \mathrm{C}$, cautions should be taken into account for the decrease of dissolved oxygen and possible increase of toxins or odors substances from

* 国家高技术研究发展计划 863 项目(2005AA60101005)和中国科学院知识创新工程重要方向项目(KZCX2-YW-426)联合 资助. 2007-12-11 收稿; 2008-01-15 收修改稿. 李杰, 男, 1982 年生, 博士研究生, E-mail: 1ijie@ihb.ac.cn.

** 通讯作者; E-mail: 1rsong@ihb.ac.cn. 
the declining bloom. In healthy Microcystis, SOD activity was about $0.06 \mathrm{U} / \mathrm{mg}$ protein, while CAT activity was too low to be measured. In addition, SOD activity increased earlier than CAT activity when Microcystis was exposed to stress conditions. CAT activity increased only when the content of chlorophyll-a began to decline. Both of the increase of SOD and CAT activities correlated negatively with the decrease of the content of chlorophyll-a though there were some exceptions. Combination of the two parameters would be potential indicator of bloom decline.

Keyword: Microcystis; decline; stress; prediction; antioxidant system

有毒蓝藻水华作为世界范围内的热点问题，目前主要集中于研究水华的发生及危害，有关水华消失 的过程, 人们知之甚少. 事实上, 浮游植物的衰亡对环境的影响与大量生长对环境的影响同等重要 ${ }^{[1-2]}$.

浮游植物死亡后，释放的有机质，特别是碳源的提供，会引发新一轮的资源竞争和种群演替，水体 生态系统发生动态改变 ${ }^{[3]}$. 在棕囊藻(Phaeocystis)死亡后, 异养细菌对浮游植物衰亡所引发的环境改变做 出了快速响应, $\alpha$-变形菌纲和拟杆菌门立即出现, 原生动物生物量也剧增 ${ }^{[4-5]}$. 浮游植物的下沉还会促进 底栖生物的消化系统消化能力, 引起食物网传递链的改变 ${ }^{[6]}$. 第二, 在细菌作用下, 死亡藻细胞被降解, 水体有机质含量急剧增加，也导致水体溶氧的急剧下降，使水体中对低溶氧敏感的生物窒息而亡，造成 巨大经济损失 ${ }^{[7]}$. 溶氧偏低常常是水华水体中鱼类死亡的主要原因，对低溶氧的敏感程度不同，导致鱼 类种群大小、年龄结构及多样性发生改变 ${ }^{[8-9]}$; 覆盖在水体底部的藻细胞, 还会损坏水体间隙水水质, 进 而影响到鱼类产卵 ${ }^{[10]}$. 第三, 浮游植物死亡后，部分有害代谢产物从细胞内溢出，如肝毒素(Microcystin), 异味物质等 ${ }^{[1,11-12]}$ 会损害水质，增加自来水处理负担的同时，对动物和人类健康造成威胁.

影响水华消失的因素有很多, 传统的观点认为, 浮游动物的捕食, 浮游植物本身不可逆的下沉对浮 游植物生物量下降的贡献最大 ${ }^{[4]}$. 近来细菌、病毒、真菌引起浮游植物生物量的下降也逐渐受到关注 ${ }^{[13-17]}$. 在浮游植物生物量达到高峰期时, 所产生的营养胁迫, 以及暴露在光、温度和毒素物质的极端条件下, 也 有可能引起细胞死亡 ${ }^{[4,18]}$.

本研究中, 在实验室条件下设计了氮饥饿、磷饥饿、黑暗、 $10^{\circ} \mathrm{C}$ 低温等四种胁迫条件, 研究微囊藻对 这些不利条件的耐受能力及在胁迫作用下的衰亡过程，进而判断这些不利条件对水华消失的可能贡献做 出评价. 就微囊藻抗氧化酶系统在四种胁迫条件的变化进行了着重研究, 对SOD和CAT能否用于指示微 囊藻群体的衰亡趋势进行了探讨.

\section{1 材料和方法}

\section{1 实验材料及培养}

铜绿微囊藻(Microcystis aeruginosa)FACHB-905 取自中国科学院水生生物研究所藻种库, 该藻株于 1998 年分离于云南滇池. 以 $\mathrm{BG} 11$ 培养基为培养介质, 正常培养条件即温度 $28^{\circ} \mathrm{C}$, 光强为 $25 \mu \mathrm{E} /\left(\mathrm{m}^{2} \cdot \mathrm{S}^{2}\right)$, 光暗周期为 $12: 12 \mathrm{~h}$. 氮饥饿与磷饥饿条件为正常 $\mathrm{BG} 11$ 培养基分别去除 $\mathrm{NaNO}_{3}$ 和 $\mathrm{K}_{2} \mathrm{HPO}_{4}$, 其他成分均与 正常培养基相同. 待微囊藻在 $1 \mathrm{~L}$ 的三角瓶中长至对数期, $4000 \mathrm{r} / \mathrm{min}$ 离心 $15 \mathrm{~min}$, 无菌水清洗藻泥 3 遍后, 分别转人氮饥饿、磷饥饿培养基中正常条件下培养, 或转人完全 $\mathrm{BG} 11$ 培养基中置于 $28^{\circ} \mathrm{C}$ 黑暗或 $10^{\circ} \mathrm{C}$ 正 常光照下培养. 氮饥饿培养基中不含 $\mathrm{NaNO}_{3}$, 磷饥饿培养基中不含 $\mathrm{K}_{2} \mathrm{HPO}_{4}$. 这四种胁迫条件在下述文中 分别简称为: $\mathrm{N}$ 饥饿、 $\mathrm{P}$ 饥饿、黑暗和低温. 以正常条件下培养作为实验对照, 每组胁迫各设 3 个平行. 最 初接种浓度 $\mathrm{OD}_{680}=0.430$, 培养基中含 $900 \mathrm{ml}$ 培养基，观察 $30 \mathrm{~d}$. 胁迫 $30 \mathrm{~d}$ 后将经过上述四种胁迫处理的 微囊藻转人正常培养条件下用 $250 \mathrm{ml}$ 的三角瓶培养, 最初接种浓度 $\mathrm{OD}_{680}=0.15$, 测定 $\mathrm{OD}_{680}$ 、叶绿素 $\mathrm{a}(\mathrm{Chl} . \mathrm{a})$ 含量以及 SOD 和 CAT 活性的变化.

\section{2 叶绿素 $a$ 的测定}

叶绿素 a 用 $80 \%$ 的丙酮提取, $4^{\circ} \mathrm{C}$ 冰箱放置 $24 \mathrm{~h}$ 后离心, 取上清测定 $\mathrm{OD}_{663}$.

$$
\text { Chl.a }(\mathrm{mg} / \mathrm{L})=12.7 \mathrm{OD}_{663}
$$

\section{3 酶液提取及酶活测定}

取适量藻样 $7000 \mathrm{r} / \mathrm{min}$, 离心 $3 \mathrm{~min}$ 后, 将藻泥悬浮于 $3 \mathrm{ml} 50 \mathrm{mmol} / \mathrm{L}$ 磷酸盐缓冲液 $(\mathrm{PBS}, \mathrm{pH}=7.8)$ 中, 
超声波破碎(每超声 $20 \mathrm{~s}$, 停 $10 \mathrm{~s}$ )共 $3 \mathrm{~min}$ 后, $8000 \mathrm{r} / \mathrm{min}$ 冷冻离心 $15 \mathrm{~min}$, 取上清液用于蛋白含量与酶活测定.

超氧化物歧化酶(SOD)的测定采用改良的 NBT 光化还原法 ${ }^{[19]}$, 核黄素浓度为 $5 \mu \mathrm{mol} / \mathrm{L}$, 其它试剂浓 度与该方法中浓度相同. 以抑制 NBT 光化还原 $50 \%$ 作为 1 个酶活单位, 计算比活.

过氧化氢酶(CAT)的测定参考董泗建等 ${ }^{[20]}$ 的方法, 由于藻细胞粗酶液呈黄绿色, 在 $365 \mathrm{~nm}$ 有较强的 吸收, 干扰结果测定, 故需将样品背景扣除. 过氧化氢酶活以每毫克蛋白质每秒钟分解 $1 \mu \mathrm{mol}$ 的过氧化 氢的量为 1 个活力单位.

蛋白含量的测定采用考马斯亮蓝-G250 染色法.

\section{4 数据处理}

对于胁迫条件下细胞内 SOD、CAT 活性是否显著上升, 进行了 ANOVA 分析，同时对 SOD、CAT 活性的变化与叶绿素 $\mathrm{a}$ 变化的关系进行了相关性分析. 分析时使用软件 SPSS $14.0, P<0.05$ 时, 具有显 著性.

\section{2 结果分析}

\section{1 四种胁迫条件对微囊藻生物量的影响}

$\mathrm{N}$ 饥饿条件下, 叶绿素 $\mathrm{a}$ 变化较敏感, 第 $3 \mathrm{~d}$ 测量即观察到叶绿素 $\mathrm{a}$ 含量下降, 但该条件下下降速率 较慢, 为 $0.02 \mathrm{mg} /(\mathrm{L} \cdot \mathrm{d})$ (图 1). 尽管叶绿素 a 含量开始下降, 但微囊藻在前 $20 \mathrm{~d}$ 仍可维持缓慢的生长. 在 $\mathrm{P}$ 饥饿前期, $\mathrm{OD}_{680}$ 与 $\mathrm{Chl} . \mathrm{a}$ 仍可持续上升. $20 \mathrm{~d}$ 后, 叶绿素 $\mathrm{a}$ 含量达到最大值, 几乎为接种浓度的 2 倍, 表明 约 $20 \mathrm{~d}$ 后细胞内的聚磷酸体才消耗殆尽. 胞内磷源消耗完后, 叶绿素 a 含量急剧的下降, 下降速率达 $0.1 \mathrm{mg} /(\mathrm{L} \cdot \mathrm{d})$, 为 $\mathrm{N}$ 饥饿条件下叶绿素 $\mathrm{a}$ 含量下降速率的 5 倍(图 1), 在四组胁迫条件中下降速率最高.
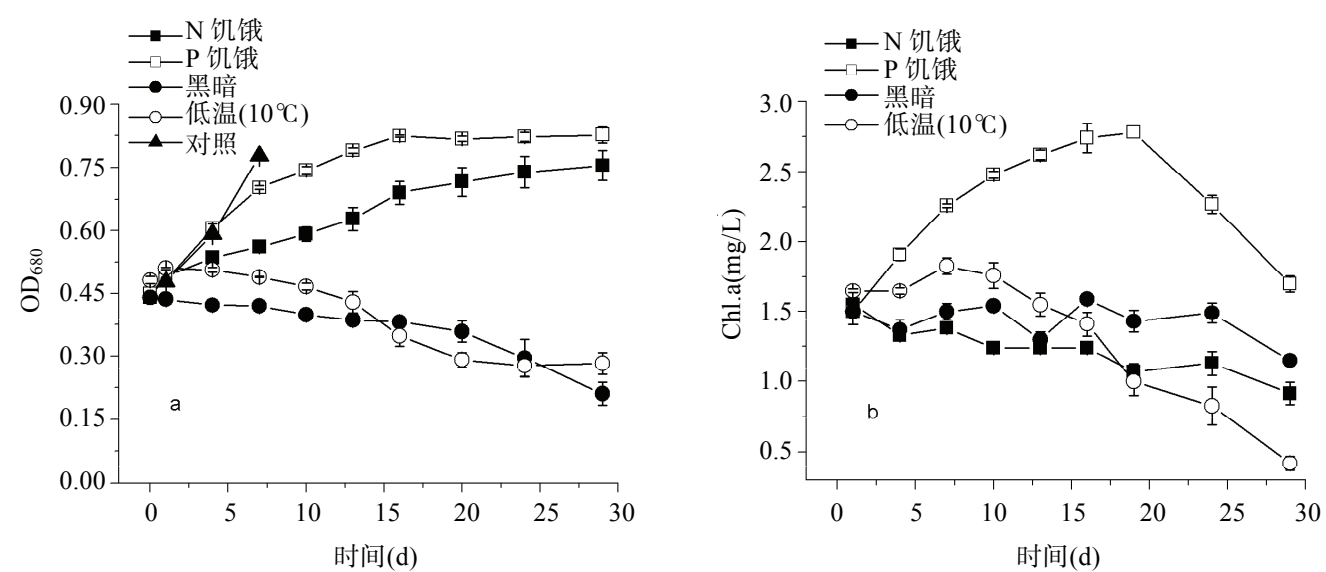

图 1 四种胁迫条件下 $\mathrm{OD}_{680}(\mathrm{a}), \mathrm{Chl} . \mathrm{a}$ 含量(b)的变化

Fig.1 Effects of four stresses on $\mathrm{OD}_{680}$ (a) and content of Chl.a (b)

与营养胁迫导致的微囊藻衰亡相比，在物理因子胁迫下，微囊藻在胁迫初期 $\mathrm{OD}_{680}$ 未表现出明显上 升. 在黑暗条件下, $\mathrm{OD}_{680}$ 和 $\mathrm{Chl} . \mathrm{a}$ 在前 $20 \mathrm{~d}$ 基本维持稳定, 此后才出现快速下降, 叶绿素 a 下降速率为 $0.06 \mathrm{mg} /(\mathrm{L} \cdot \mathrm{d})$, 为 $\mathrm{N}$ 饥饿条件下降速率的 3 倍. 表明在没有能量供应的情况下, 生长旺盛的微囊藻细胞仍 可利用现有能量维持 $25 \mathrm{~d}$ 左右生存需求. 在低温条件下, 微囊藻经历 $7 \mathrm{~d}$ 的缓慢生长后, 生物量开始下降, 叶绿素 $\mathrm{a}$ 下降速率为 $0.07 \mathrm{mg} /(\mathrm{L} \cdot \mathrm{d})$, 为 $\mathrm{N}$ 饥饿条件下下降速率的 3.5 倍.

比较这四种胁迫条件对微囊藻生物量的影响, 胁迫开始后, 叶绿素 a 含量开始下降时间顺序为 $\mathrm{N}$ 饥 饿 (1d) $>$ 低温 $(7 \mathrm{~d})>\mathrm{P}$ 饥饿 (20d) $>$ 黑暗(25d). 叶绿素 $\mathrm{a}$ 下降速率为 $\mathrm{P}$ 饥饿 $>$ 低温 $>$ 黑暗 $>\mathrm{N}$ 饥饿. 这一结果表明, 营养胁迫不如物理因子胁迫会在短期内抑制微囊藻生长, 但在长时间内, 营养胁迫特别是 P 胁迫, 会造 成微囊藻的急剧衰减. 


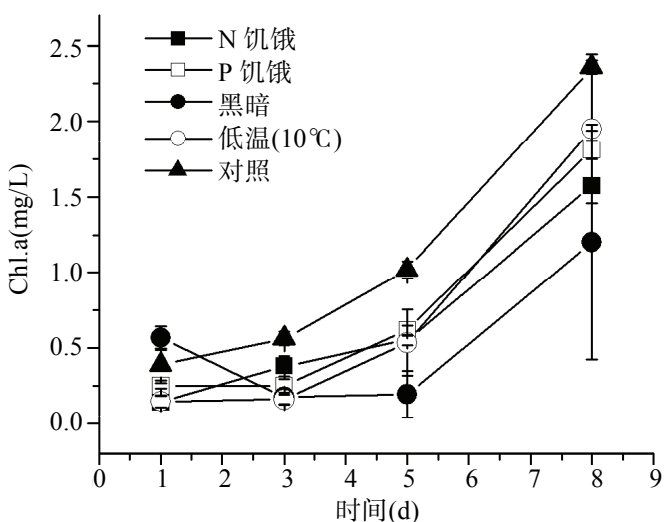

图 2 胁迫 $30 \mathrm{~d}$ 后恢复过程中叶绿素 a 含量的变化

Fig.2 Recovery of Chl.a after inoculating into optimal growth condition
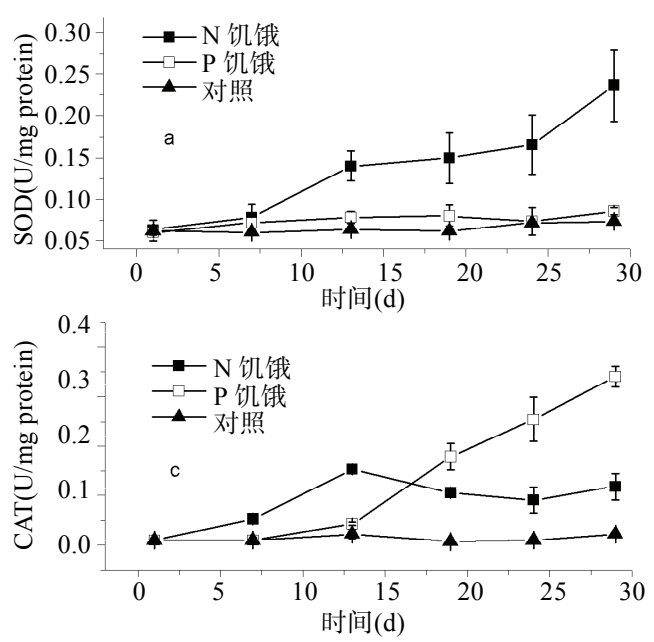

经过胁迫处理的微囊藻细胞在转人正常 条件下培养, $5 \mathrm{~d}$ 后均可正常快速生长(图 2). 第 $5 \mathrm{~d}, \mathrm{~N}$ 饥饿, $\mathrm{P}$ 饥饿, 黑暗, 低温处理的比 生长速率分别为 $0.35 、 0.36 、 0.61 、 0.43 \mathrm{~d}^{-1}$, 高 于对照的比生长速率 $0.28 \mathrm{~d}^{-1}$.

\section{2 酶系统对四种胁迫条件的响应}

$\mathrm{N}$ 饥饿条件下, 微囊藻 SOD 与 CAT 活 性显著上升(ANOVA, $P<0.05)$, 但 $13 \mathrm{~d}$ 后, 两 者活性均维持稳定(ANOVA, $P>0.05$ ), 但在 $\mathrm{P}$ 饥饿条件下, SOD 活性未观察到显著性改变, 即使在叶绿素 a 含量快速下降阶段, 而在这 段时间内, CAT 活性明显升高(ANOVA, $P<0.05$ ), 且以较稳定速率上升(图 3a, 图 3c).
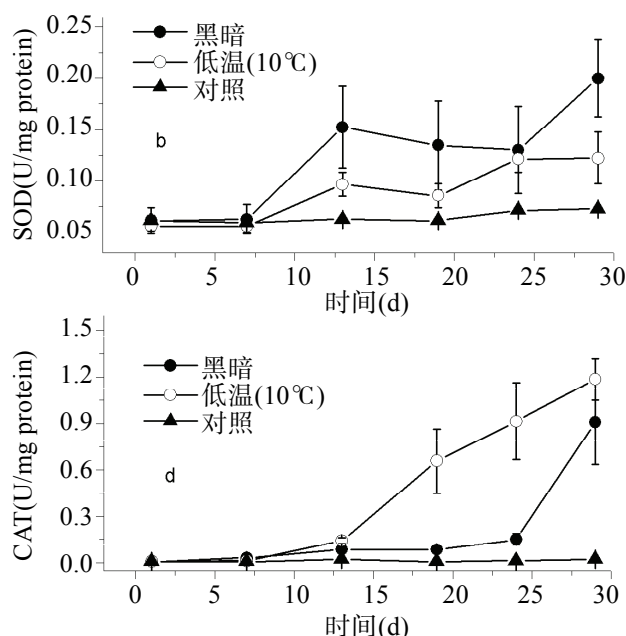

图 3 四种胁迫条件对微囊藻 SOD 和 CAT 活性的影响 (a 和 $\mathrm{c}: \mathrm{N}$ 饥饿和 P 饥饿; $\mathrm{b}$ 和 $\mathrm{d}$ : 黑暗和低温) Fig. 3 Response of SOD and CAT to the stresses (a and c: N starvation and P starvation; b and d: Dark and $10^{\circ} \mathrm{C}$ )

在黑暗与低温条件下, $\mathrm{SOD}$ 与 CAT 活性均显著上升(ANOVA, $P<0.05$; 图 3b, 图 3d). 但在黑暗条件下, 两者活性的上升主要由酶液中蛋白含量的下降所致. 在低温条件下, $\mathrm{SOD}$ 活性在 $13 \mathrm{~d}$ 显著上升后 $(P<0.05)$, 维持稳定, 但 $\mathrm{CAT}$ 活性在后期仍显著上升 $(P<0.05)$.

综观这一结果, 微囊藻在受到胁迫后, SOD 和 CAT 都会上升, 但两者上升过程表现方式不同, SOD在 胁迫下上升后保持稳定, 而 CAT 在胁迫前期升幅较小, 而在胁迫后期可观察到大幅度的上升, 两者活性 的上升与叶绿素 a 含量的下降呈负相关(表 1).

表 1 SOD, CAT 活性的上升与叶绿素 a 含量下降的相关性

Tab.1 Relationship between the SOD, CAT activity and the content of Chl.a

\begin{tabular}{|c|c|c|c|c|c|}
\hline \multirow{2}{*}{ 胁迫 } & \multicolumn{2}{|c|}{ SOD } & \multicolumn{2}{|c|}{ CAT } & \multirow{2}{*}{ 观测数 } \\
\hline & Spearman 系数 & Sig. (2-tailed) & Spearman 系数 & Sig.(2-tailed) & \\
\hline $\mathrm{N}$ 饥饿 & -0.943 & $0.005^{* *}$ & -0.657 & 0.156 & 6 \\
\hline P 饥饿 & -0.500 & 0.667 & -1.000 & $0.000^{* *}$ & 3 \\
\hline 黑暗 & -0.986 & $0.000^{* *}$ & -0.812 & $0.050^{*}$ & 6 \\
\hline 低温 $\left(10^{\circ} \mathrm{C}\right)$ & -0.886 & $0.019^{*}$ & -0.943 & $0.005^{* *}$ & 6 \\
\hline
\end{tabular}

$* P<0.05$, 相关显著; $* * P<0.01$, 相关极显著. 


\section{3 讨论}

\section{1 环境因子对微囊藻消亡的影响}

$\mathrm{N}$ 和 $\mathrm{P}$ 都是生命中不可或缺的元素. 在藻类中, $\mathrm{N}$ 还是合成藻蓝蛋白和叶绿素 $\mathrm{a}$ 必须的元素. 在 $\mathrm{N}$ 饥 饿条件下, 藻蓝蛋白做为 $\mathrm{N}$ 库降解, 叶绿素 $\mathrm{a}$ 含量下降, 光合作用降低, 细胞代谢速率减缓 ${ }^{[21]}$, 最后可以 以类似休眠体的形式长期生存 ${ }^{[22-23]} . \mathrm{P}$ 是组成细胞膜上磷脂、核酸、ATP 的基本元素, $\mathrm{P}$ 元素的缺乏必将 导致细胞无法正常代谢而死亡. 但由于微囊藻在 P 源丰富时可积累磷可形成聚磷酸体 ${ }^{[24]}$, 因此在本实验 中, 磷饥饿 $20 \mathrm{~d}$ 后才观察到急剧衰减, 这与 Sbiyyaa 等的研究结果一致 ${ }^{[25]}$. 微囊藻这种储存 N 和 P 的能力 使得他们在水体中营养缺乏时可以继续维持生长繁殖 ${ }^{[25]}$. 虽然磷饥饿不如其它物理因子能在几天内即抑 制微囊藻生长, 但在长时间内, 从磷饥饿导致叶绿素 $\mathrm{a}$ 下降的剧烈程度看, 微囊藻对 $\mathrm{P}$ 胁迫的耐受能力最 弱, 在几种胁迫条件中下降速率最快. 在胁迫 $30 \mathrm{~d}$ 后遇到合适的生长环境, 微囊藻仍可快速恢复, 因此要 控制控制微囊藻水华, 控制磷源的输人尤为重要.

对于专性光合自养的生物, 光照是其能量的唯一来源, 因而对其生物量有着极大的影响, 如 Dunaliella tertiolecta 在无光条件下, $8 \mathrm{~d}$ 内培养液即变得澄清 ${ }^{[26]}$. 微囊藻在不利条件下沉人水体底部后, 或者由于表层水华的遮光, 细胞可能因受到光胁迫而裂解. 在本实验中, 生长旺盛的微囊藻细胞仍可利 用现有能量维持 $25 \mathrm{~d}$ 左右生存需求. 常认为微囊藻在冬季下沉进人水底, 在低温条件下, 藻细胞可以通 过维持在休眠状态减缓能量代谢, 降低能耗的下降速率得以生存, 研究报道称在低温 $\left(8^{\circ} \mathrm{C}\right)$ 黑暗的情况下 可以存活很长时间 ${ }^{[27]}$, 但具体多久没有详细报道, 具体存活率尚待进一步研究.

温度是促进藻类生长最基本的环境因子 ${ }^{[28]}$. 水温的季节变化是滇池、太湖微囊藻水华季节波动的主 要因子 ${ }^{[29-30]}$. 水温也是湖泊水华预警模型中最重要的参数 ${ }^{[31-32]}$. 在本实验中, $10^{\circ} \mathrm{C}$ 下微囊藻可以维持 $7 \mathrm{~d}$ 的缓慢生长, 之后生物量快速下降. 也有研究报道, $15^{\circ} \mathrm{C}$ 以下微囊藻停止生长繁殖 ${ }^{[33]}$. Visser ${ }^{[34]}$ 等的研究 表明, 在低温下微囊藻蛋白合成缓慢, 不能正常生长, 同时碳水化合物含量增加, 细胞下沉. 这也与野外 结果一致, 在野外, 微囊藻水华常发生在温度较高的夏季与秋季, 而在冬季衰亡 ${ }^{[35]}$.

根据实验结果, 在长期没有外来 $\mathrm{P}$ 源供给而内部又无可得 $\mathrm{P}$ 源的水体中、或者水温急剧下降到 $10^{\circ} \mathrm{C}$ 以下时, 微囊藻水华可能会快速衰亡, 相应的应急措施应准备到位, 以尽量减轻水体微囊藻水华衰亡带 来的损失.

\section{2 抗氧化酶系统的变化}

对于实验室的藻类培养物，仅根据培养物眼色、叶绿素 a 或者光密度的变化就可以判断，培养物是处 于生长期, 稳定期还是处于衰亡期. 但对于野外样品, 由于风吹浪打, 浮游植物不断的被转移, 在采样点 生物量的变化并不一定反应微囊藻水华的发展趋势. 采用特定的生理指标, 反应微囊藻的代谢状态, 进 而可以预测水华的发展趋势. 由于光合能力在一天中差异较大, 不断的波动 ${ }^{[36-37]}$, 因此光合系统并不适 宜做为此类指标. 在胁迫条件下，自由基的产生与清除失去平衡，活性氧含量会增加. 过量的氧自由基 破坏脂体、蛋白、DNA, 引起细胞内抗坏血酸等抗氧化剂的减少, 氧自由基还可改变一些酶的还原状态, 从而改变酶活 ${ }^{[38]}$. 细胞通过提高抗氧化物酶活系统酶活以及抗氧化剂含量来清除过量的氧自由基. 理论 上可以根据藻细胞抗氧化酶系统的变化反应藻细胞状态, 进而预测水华发展趋势.

在本研究中, 四种胁迫处理, 除磷胁迫外 SOD、CAT 活性均比对照要高. 卿人韦等 ${ }^{[39]}$, 吴忠兴等 ${ }^{[40]}$ 也观察到在胁迫条件下 SOD、CAT 活性显著上升. 统计分析发现, 两者活性的上升与叶绿素 a 含量的下 降整体呈负相关. 但也有个别案例, 如磷饥饿下, SOD 活性未见上升, 因此可以考虑将两者结合反应野外 微囊藻的生长状态, 进而反应水华发展趋势, 有关其应用可行性将进一步研究.

需要指出的是, 在微囊藻细胞中, SOD 与 CAT 的酶活表达方式存在差异, 正常生长的藻细胞, SOD 活 性较高, 容易测定, 而 CAT 活性则较弱. 因此我们推测, 在正常条件下, 微囊藻主要依靠 SOD 清除氧自 由基, SOD 在清除 $\mathrm{O}_{2}{ }^{-}$的同时，也歧化 $\mathrm{O}_{2}{ }^{-}$产生 $\mathrm{H}_{2} \mathrm{O}_{2}, \mathrm{H}_{2} \mathrm{O}_{2}$ 可由 $\mathrm{CAT}$ 催化分解生成 $\mathrm{H}_{2} \mathrm{O}$ 和 $\mathrm{O}_{2}$. CAT 活性只 在胁迫到一定程度后才有着明显的升高, 这就表明 CAT 是诱导酶. $\mathrm{H}_{2} \mathrm{O}_{2}$ 作为其底物, 可能大量产生后才 诱导其表达, 而在正常情况下经由 SOD 所产生的 $\mathrm{H}_{2} \mathrm{O}_{2}$ 不能诱导其表达, 是否在胁迫条件下 SOD 活性上 升后造成 $\mathrm{H}_{2} \mathrm{O}_{2}$ 水平的升高, 还是存在其他途径产生过量 $\mathrm{H}_{2} \mathrm{O}_{2}$, 都有待进一步研究. 


\section{4 参考文献}

[1] Lee DY, Rhee GY. Kinetics of cell death in the Cyanobacterium Anabaena flos-aquae and the production of dissolved organic carbon. J Phycol, 1997, 33(6): 991-998.

[2] Agustí S, Alou EVA, Hoyer MV et al. Cell death in lake phytoplankton communities. Freshwater Biol, 2006, 51(8): $1496-1506$.

[3] Llabres M, Agusti S. Picophytoplankton cell death induced by UV radiation: Evidence for oceanic Atlantic communities. Limnol Oceanogr, 2006, 51(1): 21-29.

[4] van Boekel WHM, Hansen FC, Riegman R et al. Lysis-induced decline of a Phaeocystis spring bloom and coupling with the microbial foodweb. Mar Ecol Prog Ser, 1992, 81: 269-276.

[5] Brussaard CPD, Mari X, Bleijswijk JDL et al. A mesocosm study of Phaeocystis globosa (Prymnesiophyceae) population dynamics: II. Significance for the microbial community. Harmful Algae, 2005, 4(5): 875-893.

[6] Stead RA, Thompson RJ. The effect of the sinking spring diatom bloom on digestive processes of the cold-water Protobranch Yoldia hyperborea. Limnol Oceanogr, 2003, 48(1): 157-167.

[7] Skei J, Larsson P, Rosenberg R et al. Eutrophication and contaminants in aquatic ecosystems. AMBIO, 2000, 29(4): $184-194$.

[8] Maloney TE, Carnes RA. Toxicity of a Microcystis waterbloom from an Ohio pond. Ohio J Sci, 1966, 66: 514-517.

[9] Conte FS, Cubbage JS. Phytoplankton and Recreational Ponds. Washington, U.S. Western Regional Aquaculture Center Extension Publication, 2001, 105: 1-6.

[10] Harrod TR, Theurer FD. Sediment. In: Haygarth PM, Jarvis SC eds. Agriculture, hydrology and water quality. Wallingford UK: CABI Publishing, 2002: 155-170.

[11] Mazur H, Plinski M. Stability of cyanotoxins, microcystin-LR, microcystin-RR and nodularin in seawater and BG-11 medium of different salinity. Oceanologia, 2001, 43(3): 329-339.

[12] Ross C, Santiago-Vazquez L, Paul V. Toxin release in response to oxidative stress and programmed cell death in the cyanobacterium Microcystis aeruginosa. Aquat Toxicol, 2006, 78: 66-73.

[13] Caiola MG, Pellegrini S. Lysis of Microcystis aeruginosa(Kuetz.) by Bdellovibrio-like bacteria. J Phycol, 1984, 20(4): 471-475.

[14] Guixa-Boixereu N, Lysnes K, Pedros-Alio C. Viral lysis and bacterivory during a phytoplankton bloom in a coastal water microcosm. Appl Environ Microbiol, 1999, 65(5): 1949-1958.

[15] Hewson I, O'Neil JM, Dennison WC. Virus-like particles associated with Lyngbya majuscula(Cyanophyta; Oscillatoriacea) bloom decline in Moreton Bay, Australia. Aquat Microb Ecol, 2001, 25(3): 207-213.

[16] Honjo M, Matsui K, Ueki M et al. Diversity of virus-like agents killing Microcystis aeruginosa in a hyper-eutrophic pond. $J$ Plankton Res, 2006, 28(4): 407-412.

[17] Sigee DC, Selwyn A, Gallois P et al. Patterns of cell death in freshwater colonial cyanobacteria during the late summer bloom. Phycologia, 2007, 46(3): 284-292.

[18] Riegman R, Winter C. Lysis of plankton in the non-stratified southern North Sea during summer and autumn 2000. Acta Oecol, 2003, 24(1001): 133-138.

[19] 李合生. 植物生理生化实验原理和技术. 北京: 高等教育出版社, 2000: 167-169.

[20] 董泗建, 刘昌玲. 一种测定过氧化氢酶活性的新方法. 军事医学科学院院刊, 1995, 19(2): 130-132.

[21] Sauer J, Schreiber U, Schmid R et al. Nitrogen starvation-induced chlorosis in Synechococcus PCC 7942. Low-level photosynthesis as a mechanism of long-term survival. Plant Physiol, 2001, 126(1): 233-243.

[22] Brussaard CPD, Noordeloos AAM, Riegman R. Autolysis kinetics of the marine diatom Ditylum brightwellii (Bacillariophyceae) under nitrogen and phosphorus limitation and starvation. J Phycol, 1997, 33(6): 980-987.

[23] Peters E, Thomas DN. Prolonged nitrate exhaustion and diatom mortality: a comparison of polar and temperate Thalassiosira species. J Plankton Res, 1996, 18(6): 953-968.

[24] Jacobson L, Halmann M. Polyphosphate metabolism in the blue-green alga Microcystis aeruginosa. J Plankton Res, 1982, 4(3): 481-488.

[25] Sbiyyaa B, Loudiki M, Oudra B. Nitrogen and phosphorus intracellular capacity in storage by Microcystis aeruginosa Kuetz 
and Synechocystis sp.: toxic cyanobacteria occasionally forming blooms in Marrakesch area(Morocco). Ann Limnol, 1998, 34(3): $247-257$.

[26] Segovia M, Haramaty L, Berges JA et al. Cell death in the unicellular Chlorophyte Dunaliella tertiolecta. A hypothesis on the evolution of apoptosis in higher plants and metazoans. Plant Physiol, 2003, 132(1): 99-105.

[27] Tsujimura S, Tsukada H, Nakahara H et al. Seasonal variations of Microcystis populations in sediments of Lake Biwa, Japan. Hydrobiologia, 2000, 434(1): 183-192.

[28] 孙慧群, 朱 琳, 高文宝. 淡水湖泊中微囊藻水华的成因分析. 生物学通报, 2005, 40(8): 23-24.

[29] 刘丽萍. 滇池水华特征及成因分析. 环境科学研究, 1999, 12(5): 36-37.

[30] 陈宇炜, 秦伯强, 高锡云. 太湖梅梁湾藻类及相关环境因子逐步回归统计和蓝藻水华的初步预测. 湖泊科学, 2001, 13(1): 63-71.

[31] 曾 勇, 杨志峰, 刘静玲. 城市湖泊水华预警模型研究. 水科学进展, 2007, 18(1): 79-85.

[32] Robson BJ, Hamilton DP. Three-dimensional modelling of a Microcystis bloom event in the Swan River estuary, Western Australia. Ecol Model, 2004, 174(1-2): 203-222.

[33] Robarts RD, Zohary T. Temperature effects on photosynthetic capacity, respiration, and growth rates of bloom-forming cyanobacteria. New Zeal J Mar Freshwat Res, 1987, 21(3): 391-399.

[34] Visser PM, Ibelings BW, Mur LR. Autunmal sedimentation of Microcystis spp. as result of an increase in carbohydrate ballast at reduced temperature. J Plankton Res, 1995, 17(5): 919-933.

[35] Shukla B, Rai L. Potassium-induced inhibition of photosynthesis and associated electron transport chain of Microcystis: Implication for controlling cyanobacterial blooms. Harmful Algae, 2006, 5(2): 184-191.

[36] Lorenzen CJ. Diurnal variation in photosynthetic activity of natural phytoplankton Populations. Limnol Oceanogr, 1963, 8(1): $56-62$.

[37] Häder DP, Lebert M, Mercado J et al. Photosynthetic oxygen production and PAM fluorescence in the brown alga Padina pavonica measured in the field under solar radiation. Mar Biol, 1996, 127(1): 61-66.

[38] Collen J, Davison IR. Reactive oxygen production and damage in Intertidal Fucus spp. (Phaeophyceae). J Phycol, 1999, 35(1): 54-61.

[39] 卿人韦, 叶华勋, 李 扬等. 在高强度光照胁迫下极大螺旋藻两种抗氧化酶活力变化的研究. 四川大学学报(自然科学 版), 2003, 40(3): 565-569.

[40] Wu ZX, Gan NQ, Huang Q et al. Response of Microcystis to copper stress-Do phenotypes of Microcystis make a difference in stress tolerance? Environ Pollut, 2006, 147(2): 324-330. 